\title{
Potensi Hidden Canyon Beji Guwang Sebagai Daya Tarik Wisata Alam di Desa Guwang Kecamatan Sukawati, Gianyar
}

Filia Eka Risti a, 1,I Putu Anom a,2

1filieka@yahoo.com,2putuanom@unud.ac.id

a Program Studi S1 Destinasi Pariwisata, Fakultas Pariwisata,Universitas Udayana, Jl. Dr. R. Goris, Denpasar, Bali 80232 Indonesia

\section{Abstract}

Potential Beji Guwang Hidden Canyon with the beauty of the river that flanked by rocks cliff, this natural beauty can be enjoyed by doing tracking to find a good spot to take photo. Beji guwang hidden canyon present a unique view of nature to tourist that can not be find in another place in bali, this is why I choose this topic "Potential of Beji guwang hidden canyon as a nature tourist attraction in Guwang village Sukawati district, Gianyar"

The type and data resources that used in this research are qualitative data, primer and secondary data. This collecting data method was done by observation, in depth interview and documentation by research instrument by in form of interview guide lines. Data analysis that been use was interactive data analysis by use $4 A$ component and SWOT analysis matriks to extract and analysis the potential in Beji Guwang Hidden Canyon

The result of the research show that the potensial Beji guwang hidden canyon has is quiet big because having more than one nature tourist attraction. In addition of a tourism activity in Beji Guwang Hidden canyon getting a good respond from the local government and local people. Beji Guwang Hidden Canyon has a big potential, even though there are lack of knowledge in management and development that must be completed. So that the development of Beji Guwang Hidden Canyon can have a good progress.

\section{Keywords: Potential, Canyon, Nature Attraction}

\section{PENDAHULUAN}

Kabupaten Gianyar adalah salah satu kabupaten di Bali yang sudah sangat berkembang di sektor pariwisata. Kabupaten Gianyar merupakan salah satu daerah tujuan wisata internasional dan nasional, Gianyar memiliki berbagai daya tarik wisata yang kaya akan khasanah seni, budaya dan kerajinan tangan dimana hal tersebut telah menjadi daya tarik bagi wisatawan. Menurut SK nomor 29/1988 tanggal 10 Februari 1988 yang dikeluarkan oleh Pemerintah Kabupaten Gianyar tentang penetapan objek-objek wisata Kabupaten Gianyar memiliki 46 obyek wisata yang terdiri dari obyek wisata alam, museum, peninggalan purbakala, pusat kesenian, pusat kerajinan dan sebagainya. Destinasi wisata alam di Kabupaten Gianyar didominasi wisata yang berkaitan dengan air seperti Air Terjun Tegenungan, Air Terjun Kanto Lampo, Bukit Campuhan, Pantai Lebih, Sungai Ayung dan masih banyak lagi potensi-potensi wisata alam lainnya yang dimiliki Kabupaten Gianyar. Namun tidak semua daya tarik yang memiliki potensi tersebut dikelola dengan baik dan mendapat perhatian dari Pemerintah dan pihak swasta, sehingga banyak kendala-kendala yang belum dapat diatasi secara maksimal seperti minimnya sarana dan prasarana penunjang kegiatan pariwisata, kurangnya sumber daya manusia yang berkualitas dan sebagainya. Dengan pengelolaan masyarakat yang seadanya, tentu belum dapat melayani kebutuhan para wisatawan yang berkunjung. Salah satu kecamatan di Kabupaten Gianyar yang terkenal adalah Kecamatan Sukawati, daya tarik wisata yang paling sering dikunjungi wisatawan jika datang ke Sukawati adalah pasar seninya, yaitu Pasar Seni Sukawati, karena pasar ini menjual pakaian dan barangbarang hasil kerajinan seni khas masyarakat lokal.Namun tidak hanya pasar seni, di Kecamatan Sukawati juga memiliki daya tarik wisata alam yang sangat unik dan menarik bahkan belum ada daya tarik sejenis ini di Bali, yaitu Hidden Canyon Beji Guwang, daya tarik wisata ini menawarkan pemandangan sungai yang diapit oleh tebing-tebing batudisamping kiri kananya yang berwarna hitam kecoklatan, khas pemandangan Canyon layaknya Grand Canyon di Colorado Amerika. Pemandangan unik hidden canyon ini telah berhasil menarik minat wisatawan untuk datang berkunjung melihat-lihat pemandangan alam sambil menyusuri sungai dan bahkan datang hanya untuk mengambil foto diantara tebing-tebing curam. Dari berbagai macam kegiatan wisata dan potensi yang dimiliki Hidden Canyon Beji Guwang ini, maka penelitian ini ingin mengidentifikasi potensi Hidden Canyon Beji Guwang secara mendalam dan lebih 
mengetahui kendala apa yang dihadapi pengelola untuk mengembangkan daya tarik wisata Hidden Canyon Beji Guwang ini.

\section{TINJAUAN PUSTAKA}

Penelitian ini menggunakan beberapa pedoman konsep dan teori untuk menganalisis data yang didapat di lapangan, yaitu:

1. Konsep Pariwisata merupakan berbagai macam kegiatan wisata dan didukung berbagai fasilitas serta layanan yang disediakan oleh stake holder (UU No.10 Tahun 2009 tentang Kepariwisataan)

2. Tinjauan Tentang Potensi wisata. Dalam penelitian ini potensi dalam wisata dibagi menjadi tiga macam, yaitu: Potensi Alam, Potensi Kebudayaan, Potensi Buatan Manusia (Nyoman S.Pendit 1999)

3. Tinjauan Tentang Daya Tarik Wisata atau "tourist attraction", yaitu segala sesusatu yang sering menjadi daya tarik bagi orang untuk mengunjungi suatu daerah tertentu (A. Yoeti, 1985)

4. Konsep Wisata Alam dapat diartikan sebagai suatu bentuk rekreasi dan pariwisata yang memanfaatkan potensi sumber daya alam dan ekosistemnya, baik dalam bentuk asli maupun setelah adanya perpaduan dengan daya cipta manusia (Sumardjan, 1988).

5. Konsep Tentang Komponen Pariwisata. Berkembangnya pariwisata sangat tergantung pada empat faktor yaitu: Attraction (daya tarik): Site attraction dan Event attraction, Amenities (fasilitas), Accessbility, Tourist Organization, (Direktorat Jendral Pariwisata Republik Indonesia)

6. Teknik Analisis SWOT merupakan metode yang digunakan untuk menggambarkan kondisi dan mengevaluasi suatu masalah, yang berdasarkan faktor internal (dalam) dan faktor eksternal (luar) yaitu Strengths, Weakness, Opportunities, dan Threats yang akan dilakukan. (Rangkuti,2005)

\section{METODE}

Penelitian daya tarik wisata alam Hidden Canyon Beji Guwang ini dilakukan di Desa Guwang, Kecamatan Sukawati, Kabupaten Gianyar. Adapun ruang lingkup penelitian untuk dapat memperjelas permasalahan yang akan diteliti adalah:

1. Potensi Alam, yang dimaksud potensi alam pada penelitian ini adalah kekayaan alam yang ada di sekitar Hidden Canyon Beji Guwang
2. Kendala yang dihadapi pengelola Hidden Canyon Beji Guwang, dalam hal ini kendala yang dihadapi akan dianalisis menggunakan pendekatan SWOT yaitu Kekuatan (strength), kelemahan (weakness), peluang (Opportunities) dan ancaman (treatment). Penelitian ini menggunakan penelitian kualitatif. Dimana penelitian ini akan menghasilkan data-data deskriptif berupa kata-kata yang ditulis dari orang yang diwawancarai dan perilaku orang yang diamati secara alamiah untuk dimaknai atau ditafsirkan (Adnan Mahdi dan Mujahidin,2014). Data yang ditulis dengan deskriptif berupa hasil wawancara, gambaaran umum lokasi penelitian dan sejarah. Dalam pengumpulan data menggunakan tiga teknik yaitu : Observasi Lapangan dilakukanguna melihat langsung kondisi empiris kegiatan pariwisata di Hidden Canyon Beji Guwang (Adnan Mahdi dan Mujahidin,2014), wawancara mendalam dilakukan melalui wawancara tidak terstruktur bertujuan untuk memperoleh data yang mendalam mengenai hal yang diteliti dan dilakukan dengan orangorang yang berkompeten dibidangnya, serta teknik Dokumentasi berupa foto, gambar, serta data- data terkait dengan pariwisata di Desa Guwang yang didapat dari hasil pengambilan gambar secara langsung di lapangan. Untuk menentukan informan peneliti menggunakan teknik purposive sampling dengan langkah awal menemui pemandu lokal dan kepala Desa Guwang. Teknik analisis yang digunakan pada penelitian ini adalah teknik Analisis data interaktif, Analisis data ini senada dengan yang biasa disebut teknik analisis data Deskriptif kualitatif yaitu dengan tahap Reduksi Data, Display Data (penyajian data) dan Verifikasi atau penarikan kesimpulan (Miles dan Huberman).

\section{HASIL DAN PEMBAHASAN}

Desa Guwang berada di wilayah kabupaten Gianyar Kecamatan Sukawati dengan memiliki luas wilayah 278,5 Ha. Pada tahun 2015 penduduk Desa Guwang berjumlah 6.029 jiwa. Desa guwang tidak memiliki areal hutan namun demikian Desa Guwang memiliki sentral Pengerajin Industri kecil seperti Pengerajin patung, tukang ukir dan jasa, seni budaya di Desa Guwang sangat berkembang. 
A. Potensi Pariwisata di Hidden Canyon Beji Guwang ditinjau dengan konsep 4A :

\section{Attraction}

Atraksi wisata di Hidden Canyon Beji Guwang adalah keindahan alamnya dengan sungai atau disebut "beji guwang" yang diapit oleh tebingtebing tinggi di samping kiri kanannya, layaknya Grand Canyon di sungai Colorado, Amerika. Kegiatan yang dapat dilakukan di Hidden Canyon Beji Guwang antara lain:

a) Tracking di Sungai Beji Guwang Untuk dapat melihat keindahan tebing, para pengunjung dapat melakukan tracking dengan turun kebawah menyusuri sungai yang memiliki panjang kurang lebih 750 meter, sepanjang perjalanan wisatawan akan melewati canyon yang sudah dibagi menjadi tiga tahapan canyon, guna memudahkan proses pengevakuasian jika terjadi keadaan yang darurat.

b) Pura Beji Guwang

Di bagian luar Pura terdapat sebelas buah pancuran yang digunakan masyarakat setempat untuk keperluan upacara adat. Selain itu di bawah pancuran tersebut terdapat kolam yang berisi ikan-ikan kecil, ikan-ikan ini juga dapat menjadi daya tarik tersendri karena wisatawan dapat memasukan kaki ke kolam layaknya "doctor fish" (terapi dengan menggunakan ikan kecil sebagai objek untuk menggigit kaki manusia dengan tujuan untuk menghilangkan sel-sel kulit mati yang menempel pada kulit manusia).

c) Area Perkebunan dan Persawahan masyarakat setempat.

Pada tahapan akhir tracking yang dilakukan, saat wisatawan kembali keatas menuju area parkir, mata wisatwan akan dimanjakan dengan pemandangan perkebunan ketimun, semangka, juga area persawahan yang cukup luas sembari menyusurinya.

d) Guwang Mini Zoo

Setelah melalui area perkebunan, wisatawan akan melewati perumahan masyarakat lokal Desa Guwang, disalah satu rumah wargadesa yang dilaluiterdapatGuwang mini zoo, yang berisi beraneka ragam satwa dan dapat diajak wisatawan untuk berfoto.

2. Amenities

Adapun fasilitas penunjang yang terdapat di daya tarik wisata Hidden Canyon Beji Guwang seperti Tempat parkir yang luas di samping area Pura Beji Guwang, toilet yang dapat digunakan wisatawan secara gratis dan kios-kios kecil yang menjual makanan dan minuman bagi wisatawan.

3. Accessbility

Akses jalan menuju Hidden Canyon Beji Guwang sudah memadai, dan dapat ditempuh menggunakan jenis alat transportasi darat, hal ini dikarenakan lokasi jalan masuk sudah diaspal dan berada dekat dengan daya tarik wisata Pasar Seni Guwang, sehingga memudahkan wisatawan untuk mencari lokasi daya tarik wisata ini.

4. Tourist Organization

Untuk saat ini, berdasarkan hasil rapat Desa Adat dan Desa Dinas maka dibentuklah tim persiapan pengelolaan Hidden Canyon Beji Guwang yang terdiri dari masyarakat lokal dari Desa dinas dan Desa adat untuk mengelola dan bertanggung jawab pada daya tarik wisata ini selama satu tahun mendatang terhitung awal bulan Mei 2016 hingga bulan Mei tahun 2017. Analisis Potensi Hidden Canyon Beji Guwang menurut pendekatan SWOT:

a. Strenght (kekuatan) yang dimiliki Hidden Canyon Beji Guwang: Pemandangan sungai yang dikelilingi tebing-tebing batu yang sangat indah untuk di jadikan tempat berfoto wisatawan serta lokasi Hidden Canyon Beji Guwang ini terletak dibawah perkebunan dan persawahan, hal ini dapat membuat wisatawan dapat menikmati suasana pedesaan yang asri dengan hamparan perkebunan ketimun, semangka dan persawahan.

b. Weakness (kelemahan) yang terdapat di Hidden Canyon Beji Guwang: Belum adanya aspek Keselamatan bagi wisatawan, seperti asuransi, Kurangnya kualitas SDM lokal dalam hal pengetahuan bahasa asing pada pemandu wisata, Minimnya fasilitas umum yang tersedia, seperti tempat sampah dan satu toilet umum serta Kurangnya promosi yang dilakukan pihak pengelola.

c. Opportunity (Peluang) yang dimilki oleh Hidden Canyon Beji Guwang: Letak Lokasi Hidden Canyon Beji Guwang cukup dekat dengan daya tarik wisata lain yang berada di Gianyar sehingga memudahkan wisatawan untuk mencari daya tarik wisata ini.

d. Treaths (Ancaman) yang dapat terjadi di Hidden Canyon Beji Guwang seperti: Masifnya pengembangan pariwisata di hulu sungai, dengan maksud meminimalisir pembangunan fasilitas penunjang pariwisata. 
Analisis Kondisi Hidden Canyon Beji Guwang sebagai atraksi wisata alam adalah sebagai berikut menggunakan SWOT:

1) Strategi SO

a. Pengelola Hidden Canyon Beji Guwang menjalin kerjasama dengan biro perjalanan untuk mendatangkan wisatawan setelah berwisata dari Pasar seni Guwang dan Pasar Seni Sukawati

b. Pengaturan pola pertanian dan fasilitas dijalur tracking seperti pembuatan dan perbaikan jalan setapak di jalur yang dilalui wisatawan.

2) Strategi ST

Menjalin kerjasama dengan desa sebelah untuk tetap menjaga kebersihan sungai dan kualitas air di aliran sungai.

3) Strategi WO

a. Pengelola Hidden Canyon Beji Guwang menjalin kerjasama dengan biro perjalanan untuk mendatangkan wisatawan sehingga wisatawan setelah berkunjung ke Pasar Seni Sukawati dan Pasar Seni Guwang dapat singgah di daya tarik Hidden Canyon Beji Guwang.

b. Melakukan promosi lewat berbagai media sosial maupun media cetak dan menjalin kerjasama dengan pihak biro perjalaan untuk menarik wisatawan

c. Melakukan pembinaan dan pelatihan kepada para pemandu wisata lokal khususnya pelatihan bahasa asing dan cara-cara melayani wisatawan dengan baik.

4) Strategi WT

a. Meningkatkan SDM lokal baik yang bekerja di Hidden Canyon Beji Guwang maupun tidak

b. Segera melakukan peningkatan dalam aspek keselamatan, kebersihan dan pelestarian lingkungan

\section{B. Kendala-kendala yang dihadapi pengelola Hidden Canyon Beji Guwang sebagai dayatarik wisata alam}

Berdasarkan hasil anaslisis SWOT, dapat dilihat potensi Hidden Canyon Beji Guwang menghadapi beberapa kendala, yaitu:

1. Kurangnya kualitas SDM lokal dalam hal pengetahuan bahasa asing terutama pada pemandu wisata.

2. Minimnya fasilitas umum yang tersedia, seperti tempat sampah dan toilet umum yang belum terealisasi

3. Kurangnya promosi optimal yang dilakukan pihak pengelola, seperti kerjasama dengan industri pariwisata/pihak travel agent
4. Belum adanya kerjasama antara Desa Adat Guwang dengan desa lain disekitarnya mengenai kebersihan sungai di DAS aliran sungai yang melalui Hidden Canyon Beji Guwang

5. Belum adanya pelatihan bagi pemandu lokal mengenai aspek keselamatan, keamanan dan kesehatan wisatawan atau pengunjung.

\section{SIMPULAN DAN SARAN}

\subsection{Simpulan}

Simpulan dalam penelitian ini maka dapat disimpulkan bahwa Potensi wisata yang terdapat di Hidden Canyon Beji Guwang sangat unik dan menarik, dengan keunikannya yaitu sungai Guwang yang diapit oleh tebing-tebing batu, dimana wisatawan dapat melakukan tracking menyusuri sungai dengan medan yang cukup menantang, kemudian melihat perkebunan ketimun dan semangka juga hamparan sawah milik masyarakat lokal. Tebing batu ini juga menjadi daya tarik bagi wisatawan karena menjadi spot foto yang indah. Terdapat beberapa potensi pariwisata yang mendukung seperti Pura dengan pancuran kolam "doctor fish", area persawahan dan perkebunan dan mini zoo, serta aksesbilitas dan fasilitas yang cukup memadai. Meskipun Hidden Canyon Beji Guwang memiliki potensi yang besar dan banyak, namun atraksi Hidden Canyon Beji Guwang kini masih menghadapi banyak kendala antara lain, kurangnya kualitas SDM dalam hal bahasa, minimnya fasilitas penunjang, kurangnya promosi yang optimal, dan belum adanya aspek keselamatan, kesehatan dan keamanan bagi wisatawan.

\subsection{Saran}

Adapun beberapa saran yang dapat diberikan peneliti kepada pihak pengelola Hidden Canyon Beji Guwang, yaitu:

1. Pihak pengelola Hidden Canyon Beji Guwang sebaiknya melakukan promosi mendalam melalui media cetak, media elektronik, maupun menjalin kerjasama dengan pihak biro perjalanan

2. Menambah fasilitas penunjang, seperti penambahan toilet dan tempat sampah

3. Meningkatkan aspek keselamatan bagi wisatawan terutama pada saat berada di canyon dengan cara memberikan asuransi kepada setiap wisatawan, membuat alat bantu sedemikian rupa bagi wisatawan di medan tertentu yang cukup sulit untuk dilalui 
4. Meningkatkan kualitas SDM, khususnya pemandu wisata dalam berbahasa asing agar tidak hanya dapat melayani wisatawan domestic tapi juga wisatawan mancanegara

5. Perencanaan yang dibuat melibatkan masyarakat lokal agar masyarakat ikut serta menjaga kelestarian daya tarik wisata.

\section{DAFTAR PUSTAKA}

Aditya Adiguna Hanum, I Putu.2015. “Pengembangan Potensi Pantai Echo Beach Sebagai Daya Tarik Wisata di Desa Canggu Kecamatan Kuta Utara"

Agus Mahendra Suryajaya, I Putu.2015. "Pengembangan Air Terjun Suranadi sebagai Daya Tarik Wisata Alam di Desa Jatiluwih"

Mujahidin dan Mahdi Adnan.2014.Panduan Penelitian Praktis untuk menyusun Skripsi, Tesis, dan Disertasi.Penerbit Alfabeta. Bandung

Pendit,Nyoman S.1999.Ilmu Pariwisata (Sebuah Pengantar Perdana).Jakarta.Pradnya Paramita. (Dalam laporan Penelitian Lapangan III I Wayan Nanendra Dama Gunawan)

Pendit, I Nyoman, S (1999) Ilmu Pariwisata, Sebuah Pengantar Perdana. Jakarta: PT Pradnya Paramita, cetakan ke-enam (edisi revisi).

Sugiyono. 2008. Metode Penelitian Pendidikan.Bandung:Alfabeta.

Undang-Undang No.10 Tahun 2009 Tentang Kepariwisataan

Yoeti, Oka.(1985). Pengantar Ilmu Pariwisata. Penerbit Angkasa. Bandung.

http://www.bbc.co.uk/staticarchive/1b61cdad2fd4396c5 4b4a0900c9e199416cadf4a.jpg

http://geo-mexico.com/wp-

content/uploads/2013/07/Fig19-7-ButlerModel-

color.ai_.jpg 